\title{
AN ESTIMATION METHOD FOR GREENHOUSE TEMPERATURE UNDER THE INFLUENCE OF EVAPORATIVE COOLING SYSTEM
}

\author{
Mohammad Hossein Shojaei ${ }^{1}$ Hamid Mortezapour ${ }^{1 *}$, Kazem Jafarinaeimi ${ }^{1}$, Mohammad Mehdi \\ Maharlooei $^{1}$
}

\begin{abstract}
Temperature is one of the most important plant growth parameters that should be controlled in the greenhouses. The present study was aimed to assess the thermal behavior of a greenhouse with and without the fan and pad (FP) evaporative cooling system. A method was developed to approximate the greenhouse temperature based on the mass and energy balance equations. For this purpose, both of the fan and pad evaporative cooling system, and the greenhouse were studied. The results of the theoretical analysis were compared with those achieved by the experiments. Maximum deviations of 5.32, 5.56 and $4.530 \mathrm{C}$ were observed between the theoretical and experimental temperatures of the inside air, the floor and the cover of the greenhouse without the cooling system, respectively. Whereas, the mean absolute error values associated with the predicted temperatures of the greenhouse with the FP system were ranged between 1.50 and $25.67 \%$. Based on the obtained values for the correlation coefficient, root mean square error and mean absolute magnitude error, it was concluded that the models satisfactorily predicted the temperature of the greenhouse components. An air circulation system inside the greenhouse can be proposed to maintain the lumped condition even at the high temperatures, and lead to smaller errors. The results indicated that the inside air, the floor and the cover temperature of the greenhouse reduced by respectively $20.6,13.0$ and $20.6{ }^{\circ} \mathrm{C}$ when using the FP system with the air velocity of $4.4 \mathrm{~ms}^{-1}$ and the pad thickness of $6 \mathrm{~cm}$.
\end{abstract}

Keywords: Absolute Error, Fan and Pad, Heat and Mass Transfer, Mathematical Modelling

\section{INTRODUCTION}

Due to recent developments in the greenhouse cultivation and off-season production in response to the population growth and the increase in living standards, there is an urgent necessity to provide the appropriate environmental conditions for plant growing in the greenhouse. Temperature is one of the most key factors, which normally requires the highest energy fraction. Consumption of fossil fuels is a major cause of climate change, and global warming through severe damages to the ozone layer. In particular, energy consumed for ventilation, cooling or heating of buildings, which accounts for $25-40 \%$ of the total energy consumption, is mostly consisted of fossil fuels and nonrenewable fuels such as gas, gasoline, and kerosene $[1,2]$. The prospect of ending global fossil fuel resources in the next few decades along with the competition among the countries has led to the optimization of energy consumption as a strategic policy proposed by the economists and the governors throughout the world. In recent years, a number of studies have been conducted to use renewable energies as the alternative or supplementary source of the fossil fuels in the greenhouse heating/cooling systems [3]. Total solar radiation received by a greenhouse depends on its shape and orientation. Some studies have assessed greenhouse structure and optimal greenhouse design for maximum solar energy absorption $[4,5]$.

Several attempts have been made to use simple passive methods for the greenhouse cooling with the minimum energy consumption. Impron et al [6] proposed a simple cooling model for a greenhouse in Indonesia, with a tropical climate, based on the specifications of covers that reflect infrared radiation. Garcia-Alonso et al [7] recommended new plastic covers with special coating properties to reflect the infrared rays for the greenhouses in tropical areas. Ould Khaoua et al [8] investigated a two-dimensional model using computational fluid dynamics (CFD) method to determine the greenhouse air temperature under the influence of the valve location and orientation as well as the temperature and flow rate of the air. The results showed that the wind-oriented ceiling valves had the highest

This paper was recommended for publication in revised form by Regional Editor Omid Mahian

${ }^{1}$ Department of Biosystems Engineering, Faculty of Agriculture, Shahid Bahonar University of Kerman, Kerman, Iran

*E-mail address: Mohammad.ir1390@yahoo.com; h.mortezapour@uk.ac.ir; jafarinaeimi@uk.ac.ir, maharlooei@uk.ac.ir Orcid id: 0000-0001-9783-4893; 0000-0002-3387-3639; 0000-0002-3753-1249; 0000-0001-5750-3168

Manuscript Received 26 May 2019, Accepted 02 September 2019 
ventilation rate. A one-dimensional model was developed for prediction of the temperature inside the greenhouse based on the weather station data. The predicted values in this study showed a good agreement with the measured data Kumar et al [9]. Teitel et al [10] investigated the greenhouse air temperature distribution under the natural ventilation generated by the ceiling valves using the CFD method. The results showed that the air flow pattern and the temperature distribution were significantly influenced by the valves location.

Several researchers have studied the performance of the evaporative cooling systems [11]. Ghosal et al [12] developed a mathematical model for a water-based cooling system using the wetted screens on the roof and the south wall of a greenhouse in Delhi. Validation of the model was carried out under the conditions of the shaded screen with water flow as well as pure shade without the water flow and screen. The results of comparing three types of greenhouse cooling systems in Sudan revealed that the fan and pad had the highest effectiveness due to the relatively low relative humidity of the ambient air [13]. Thermal modeling of the greenhouse components under the influence of the ambient and the system operating conditions is helpful to design an appropriate FP cooling system. Jain and Tiwari [14] developed a computer program to investigate the effect of the evaporative cooling system on the temperature distribution of a greenhouse. A good agreement between the predicted and the experimental temperatures was reported by the researchers. Thermal modeling of a greenhouse in the hot and humid climate of India indicated the suitable combination of the evaporative cooling, shading and ventilation systems for maintaining the inside condition of the greenhouse within the permissible limits throughout the year [15]. The Performance of an evaporative cooling system was experimentally investigated during the warm period in the Mediterranean climate. The results showed that the best performance of the system was obtained for a reconstruction temperature of $60{ }^{\circ} \mathrm{C}$ and flow ratio of 0.2 [16].

In this paper, an estimation method was developed based on the mass and energy balance equations of the greenhouse components to approximate the temperature variation of a greenhouse in the hot and dry conditions of Kerman, Iran. Also, the present study attempted to investigate the effect of operating parameters of the evaporative cooling system, including blower speed and pad thickness, on the temperature of the greenhouse components during the day. For this purpose, both of the FP evaporative cooling system and the greenhouse were studied together. Our survey of the literature indicated that similar study was not reported by previous researchers, so far.

\section{MATERIALS AND METHOD}

\section{Thermal Analysis of Greenhouse}

A number of methods are usually used for modelling the greenhouse temperature such as numerical, neural network, fuzzy logic, and regression methods as well as thermal analysis based on the mass and energy balance equations. Among these, the mass and energy balance equations can be easily applied to predict the greenhouse temperature, and cooling/heating load even before built. While, the other methods work based on the obtained experimental data from a constructed structure during the operating conditions. On the other hands, mathematical models achieved by the mass and energy balance equations are easily applicable for other greenhouses with different construction materials under various ambient conditions. Therefore, the present study was aimed to approximate the greenhouse temperature using the mass and energy balance equations. A schematic of the greenhouse and the evaporative cooling system is shown in figure 1. The ambient air passes through a humidifying pad by the force of the fan. The water inside the cooling pad is evaporated by absorbing the heat from the moving air. Because of this process, the dry bulb temperature of the air decreases and its relative humidity increases, while the wet bulb temperature and the enthalpy remain constant. Figure 2 illustrates the heat transfer paths from/to the greenhouse.

Theoretical analysis of the greenhouse was conducted based on the following assumptions:

- The systems are lumped so the spatial effects are not considered in the greenhouse.

- The greenhouse is without plants.

- The temperature distribution is uniform in the floor, the inside air and the cover.

- The effect of the blower on the inlet air temperature is negligible

- The solar absorption and emission coefficients of inside air are negligible.

- Solar irradiance on the east and west walls of the greenhouse are negligible. 
Journal of Thermal Engineering, Research Article, Vol. 7, No. 4, pp. 918-934, May, 2021

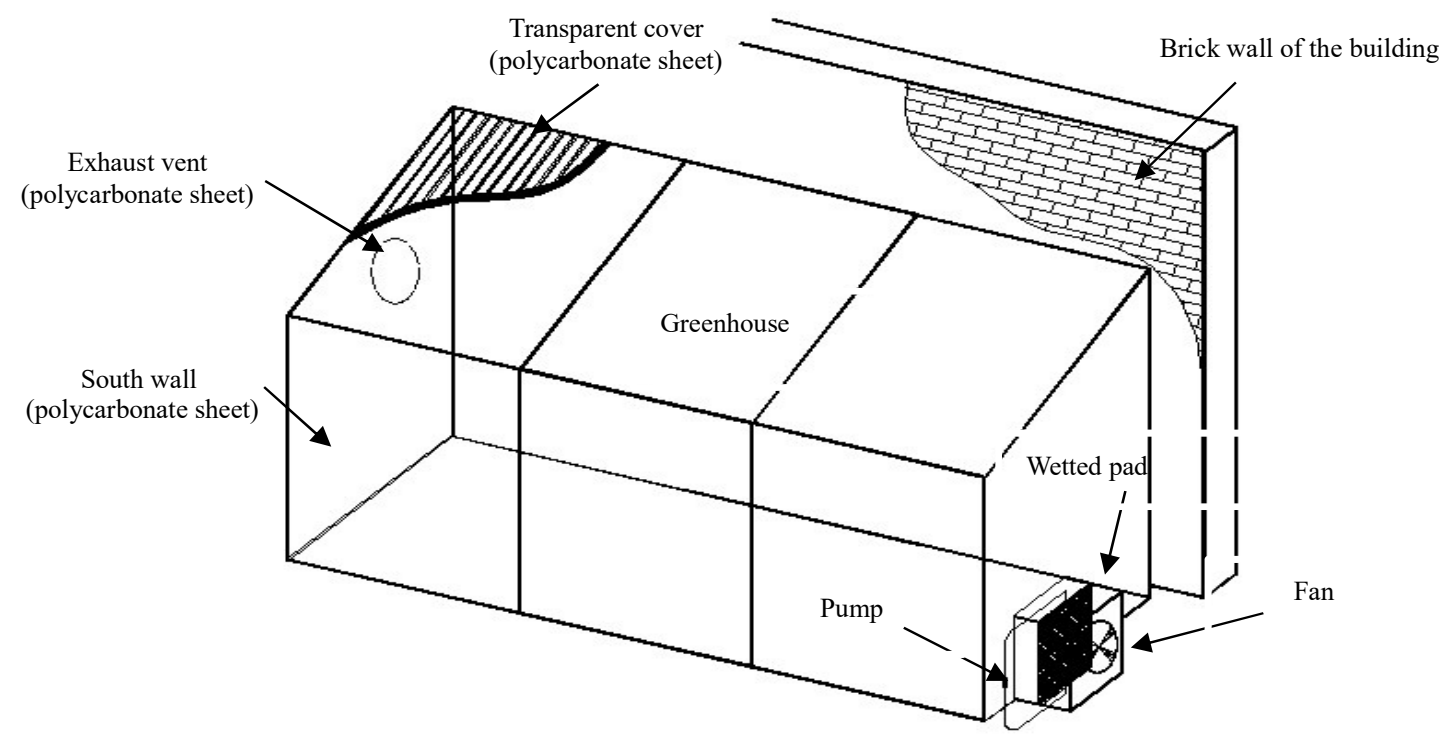

Figure 1. A schematic of the evaporative cooling system used in the experiments

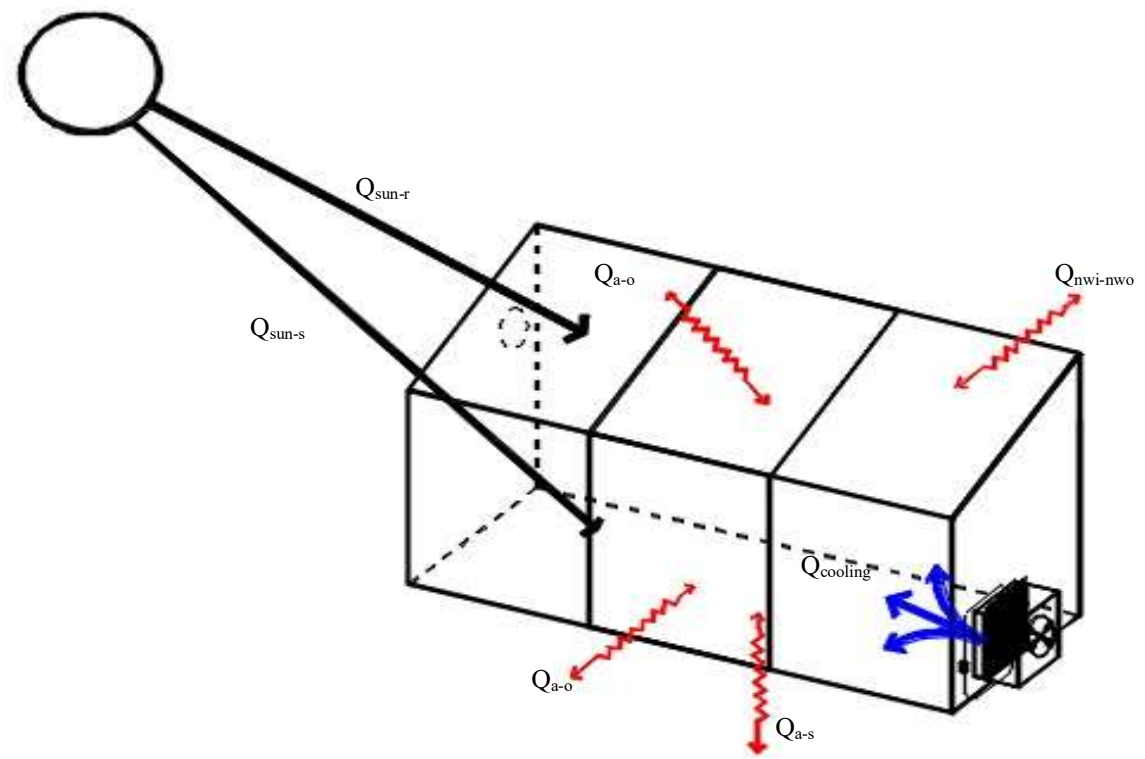

Figure 2. A diagram of heat transfer paths from/to the greenhouse

The inside air, cover and floor temperatures of the greenhouse were respectively obtained by equations 1-3 [17].

$$
\begin{aligned}
\frac{d T_{a}}{d t} & =\frac{Q_{a-s}-Q_{a-o}-Q_{a-r i}-Q_{n w i-n w o}+Q_{\text {cooling }}}{\rho_{a} C_{p-a} \forall_{a}} \\
\frac{d T_{r i}}{d t} & =\frac{Q_{s u n-r}+Q_{a-r i}+Q_{s-r}-Q_{r-o}-Q_{r-s k}}{\rho_{r} C_{p-r} \forall_{r}} \\
\frac{d T_{s}}{d t} & =\frac{Q_{s u n-s}+Q_{a-s}-Q_{s-r i}}{\rho_{s} C_{p-s} \forall_{s}}
\end{aligned}
$$


where $Q_{a-s}$ is the heat transfer rate between the inside air and the soil; $Q_{a-o}$ shows the heat transfer rate between the inside air and the surroundings; $Q_{a-r i}$ stands for the heat transfer rate between the inside air and the cover; $Q_{n w i-n w o}$ is the heat transfer rate between the inner and the outer surfaces of the north wall; $Q_{s u n-r}$ indicates the radiation heat transfer from the sun to the roof cover; $Q_{s-r i}$ the heat transfer rate between the soil and the cover; $Q_{r i-o}$ stands for the heat transfer rate between the cover and the ambient air; $Q_{r-s k}$ shows the radiation heat transfer rate from the cover to the sky; $Q_{\text {sun-s }}$ is the radiation heat transfer rate from the cover to the soil; $\rho_{a}, \rho_{r}$ and $\rho_{s}$ are the densities of the inside air, the cover and the soil, respectively; $C_{p-a}, C_{p-r}$ and $C_{p-s}$ are the specific heats of respectively the inside air, the cover and the soil; $\forall_{a}, \forall_{r}$ and $\forall_{s}$ stand for the volumes of the inside air, the cover and the floor of the greenhouse, respectively; $Q_{\text {cooling }}$ indicates the amount of the cooling load.

The rates of heat transfer (through convection or conduction) between the greenhouse components were obtained from equations 4- 7 [18, 19]

$$
\begin{gathered}
Q_{a-s}=A_{s} U_{a-s}\left(T_{a}-T_{s}\right) \\
Q_{a-r i}=A_{r} U_{a-r i}\left(T_{a}-T_{r i}\right) \\
Q_{r i-o}=A_{r} U_{r i-o}\left(T_{r i}-T_{o}\right) \\
Q_{n w i-n w o}=A_{n w} \frac{K_{n w}}{d_{n w}}\left(T_{n w o}-T_{n w i}\right)
\end{gathered}
$$

where $A_{s}, A_{r}$ and $A_{n w}$ are the surface areas of the floor, the sloped ceiling and the north wall, respectively; $K_{n w}$ is the conduction heat transfer coefficient of the north wall; $d_{n w}$ is the thickness of the north wall; $U_{a-s}, U_{a-r i}$ and $U_{r i-o}$ are the overall heat transfer coefficients between the inside air and the soil, the inside air and the cover, and the cover and the outside air, respectively; $T_{a}, T_{s}, T_{r i}, T_{o}, T_{n w o}$ and $T_{n w i}$ show the temperatures of the inside air, floor, cover, ambient, outer surface of the north wall and inner surface of the north wall, respectively.

The heat transfer coefficient between the greenhouse components can be determined by the following equations [20].

$$
\begin{aligned}
U_{a-r i} & =3\left(T_{a}-T_{r i}\right)^{\frac{1}{3}} \\
U_{a-s} & = \begin{cases}1.7\left(T_{a}-T_{s}\right)^{\frac{1}{3}} & T_{a}<T_{s} \\
1.3\left(T_{a}-T_{s}\right)^{0.25} & T_{a} \geq T_{s}\end{cases} \\
U_{r i-o} & = \begin{cases}2.8+1.2 V_{0} & V_{0}<4 \\
2.5\left(V_{0}\right)^{0.25} & V_{0} \geq 4\end{cases}
\end{aligned}
$$

The heat transfer between the inside air and the outdoor can be obtained by the equation proposed by [18]:

$$
Q_{a-o}=\rho_{a} C_{p-a} \Phi_{a-o}\left(T_{a}-T_{o}\right)
$$

where $\varphi_{a-o}$ is the volumetric exchange rate of the air between the greenhouse and the ambient, which was obtained as follow [21]:

$$
\phi_{a-o}=A_{s}\left(8.3 \times 10^{-5}+3.5 \times 10^{-5} V_{0} f_{a}\right)
$$

The absorbed heat by the soil and the greenhouse cover can be obtained from equations 13 and 14, respectively $[20]$.

$$
\begin{gathered}
Q_{\text {sun }-r}=A_{r} \alpha_{r} G_{r} \\
Q_{\text {sun }-s}=A_{s} \alpha_{s} G_{s}
\end{gathered}
$$


where $G_{r}$ and $G_{s}$ are the solar radiation intensities on the cover and the soil, respectively; $\alpha_{r}$ and $\alpha_{s}$ are respectively the absorption coefficients of the cover and the soil.

The radiation heat transfer rate between the soil and the cover, as well as between the cover and the sky were determined by equations 15 and 16, respectively [17].

$$
\begin{aligned}
& Q_{s-r}=A_{s} E_{s} E_{r i} F_{s-r i} \sigma\left(T_{s}{ }^{4}-T_{r i}{ }^{4}\right) \\
& Q_{r i-s k}=A_{r} E_{r i} \sigma\left(T_{r i}{ }^{4}-T_{s k}{ }^{4}\right)
\end{aligned}
$$

where $E_{r i}$ and $E_{s}$ are respectively the emission coefficients of the cover and the soil, $F_{s-r i}$, is the view factor between the cover and the soil, and $\sigma$ is the Stefan Boltzmann constant. To determine the temperature of the sky, the following equation was suggested by Joudi and Farhan [22].

$$
T_{s k}=0.0552\left(T_{0}\right)^{1.5}
$$

\section{Calculation of Active Cooling Load}

Since the greenhouse temperature was assumed to be uniform, the outlet temperature, which refers to the exhaust air, was taken to be equal to the greenhouse temperature. So, the sensible cooling load was determined as follow [23]:

$$
Q_{\text {cooling }}=\dot{m} C_{p-c a}\left(T_{i}-T_{g}\right)
$$

where $T_{i}$ shows the temperature of the coolant air entering the greenhouse. In the present study, the evaporative cooling system of FP was employed for the greenhouse.

The temperature drop of the air passing through the wetted pad depends on the factors such as the pad thickness, the material of the pad, the air velocity and the relative humidity of the ambient air. Typically, empirical relationships are used to determine the pad cooling efficiency and the air temperature drop in the FP system. The outlet temperature of the cooling system $\left(T_{i}\right)$ was given by Bahadori et al [24]:

$$
T_{i}=-\left(\eta{ }^{\prime}\left(T_{d b}-T_{w b}\right)-T_{d b}\right)
$$

where $T_{d b}$ and $T_{w b}$ are the dry and wet bulb temperatures of the ambient air $\left({ }^{\circ} \mathrm{C}\right)$, and $\eta$ is the cooling efficiency of the FP system. In Iran, the straws of white poplar were used usually as the cooling pad. The cooling efficiency of the straw can be determined using the following equation [24].

$$
\eta=F(u)+F(d)
$$

where $F(u)$, for the velocities lower than $5 \mathrm{~m} \mathrm{~s}^{-1}$, was obtained by equation 21 and $L(d)$ can be calculated by the following experimental expression [24]:

$$
\begin{gathered}
F(u)=-0.0681 u^{2}+0.0403 u+0.891 \\
L(d)=\left[0.04631-1.11110^{-3} d\right] \operatorname{Ln} \frac{d}{2.5}
\end{gathered}
$$

where $u$ is the velocity of the air passing through the wetted pad $\left(\mathrm{ms}^{-1}\right)$ and $d$ is the bulk thickness (m).

\section{Experimental Procedure}

To validate the results of the obtained equations, a lean-to greenhouse was constructed in the solar energy laboratory of Department of Biosystems Engineering, Shahid Bahonar University of Kerman, Iran. The greenhouse was $5 \mathrm{~m}$ long, $1.62 \mathrm{~m}$ wide, with the heights of $1.5 \mathrm{~m}$ and $2.75 \mathrm{~m}$. The greenhouse structure was made up of a steel frame (rectangular tube with the cross-section of $4 \times 4 \mathrm{~cm}$ ) covered with a $10 \mathrm{~mm}$-thick transparent polycarbonate sheet. The 
greenhouse was positioned in front of a building where the north wall was closed to the brick wall of the building (figure 3). The input parameters used for the calculation were given in Table 1.
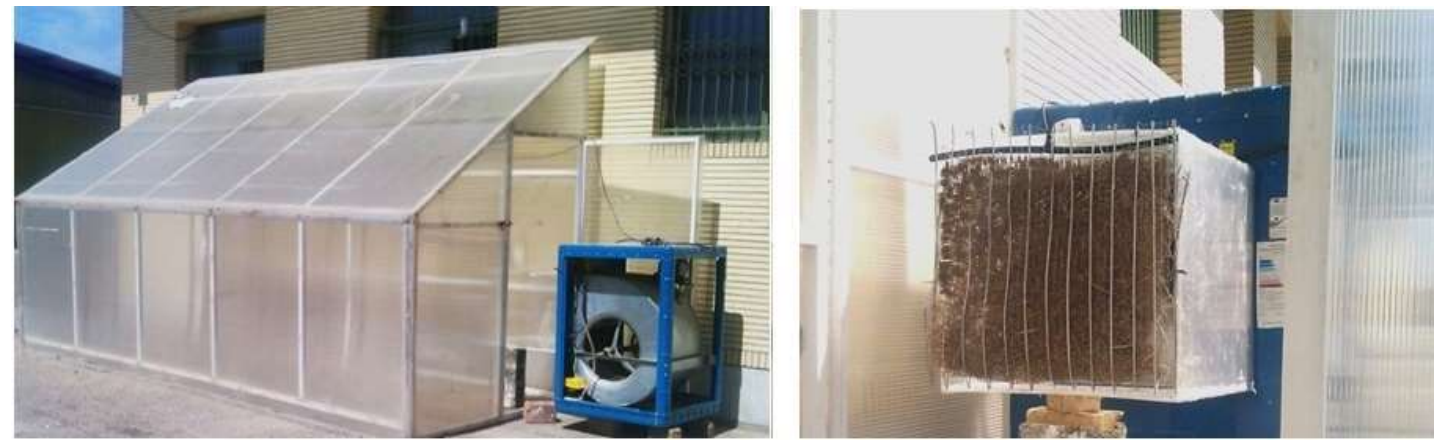

Figure 3. Photographs of the greenhouse and the evaporative cooling system

Table 1. The parameters used for the calculation

\begin{tabular}{|c|c|c|c|}
\hline Parameter & Value & Parameter & Value \\
\hline$d$ (thickness) & $0.04(\mathrm{~m})$ & $C_{p-r}$ (specific heat capacity of roof) & $400\left(\mathrm{~J} \mathrm{~kg}^{-1} \mathrm{~K}^{-1}\right)$ \\
\hline$d_{n w}$ (thickness of north wall) & $0.4(\mathrm{~m})$ & $C_{p-s}$ (specific heat capacity of soil) & $920\left(\mathrm{~J} \mathrm{~kg}^{-1} \mathrm{~K}^{-1}\right)$ \\
\hline$A_{r}($ surface area of roof $)$ & $11.74(\mathrm{~m} 2)$ & $\begin{array}{c}K_{n w} \text { (thermal conductivity of north } \\
\text { wall) }\end{array}$ & $0.427\left(\mathrm{~W} \mathrm{~m}^{-1} \mathrm{~K}^{-1}\right)$ \\
\hline$A_{S}($ surface of area soil) & $10.85\left(\mathrm{~m}^{2}\right)$ & $\sigma($ Stefan-Boltzmann constant) & $5.67 \times 10^{-8}\left(\mathrm{~W} \mathrm{~m}^{-2} \mathrm{~K}^{-4}\right)$ \\
\hline$A_{n w}($ surface area of north wall) & $12.5\left(\mathrm{~m}^{2}\right)$ & $\eta$ (efficiency of pad) & $0.22 \%$ \\
\hline$\forall_{a}($ volume of air $)$ & $86.68\left(\mathrm{~m}^{3}\right)$ & $f_{a}($ view factor of air $)$ & 1 \\
\hline$\forall_{r}$ (volume of roof) & $0.51\left(\mathrm{~m}^{3}\right)$ & $F_{s-r i}$ (view factor of soil to roof) & 0.82 \\
\hline$\forall_{S}($ volume of soil $)$ & $10.85\left(\mathrm{~m}^{3}\right)$ & $F_{r i-s k}($ view factor of roof to sky) & 0.82 \\
\hline$\rho_{a}$ (density of air) & $1.161\left(\mathrm{~kg} \mathrm{~m}^{-3}\right)$ & $E_{S}($ emission coefficient of soil) & 0.80 \\
\hline$\rho_{S}($ density of soil $)$ & $2.115\left(\mathrm{~kg} \mathrm{~m}^{-3}\right)$ & $E_{r i}$ (emission coefficient of roof) & 0.97 \\
\hline$\rho_{r}($ density of roof $)$ & $1.220\left(\mathrm{~kg} \mathrm{~m}^{-3}\right)$ & $E_{s k}($ emission coefficient of sky) & 0.80 \\
\hline$C_{p}$ (specific heat capacity) & $1000\left(\mathrm{~J} \mathrm{~kg}^{-1} \mathrm{~K}^{-1}\right)$ & $\begin{array}{c}\eta_{s-i s} \text { (absorption coefficient of solar } \\
\text { radiation by soil) }\end{array}$ & 0.86 \\
\hline $\begin{array}{c}C_{p-a} \text { (specific heat capacity of } \\
\text { air) }\end{array}$ & $1000\left(\mathrm{~J} \mathrm{~kg}^{-1} \mathrm{~K}^{-1}\right)$ & $\begin{array}{c}\eta_{r i-i s} \text { (absorption coefficient of } \\
\text { solar radiation by roof) }\end{array}$ & 0.0173 \\
\hline
\end{tabular}

The experiments were carried out from 9 a.m. to 5 p.m. on the days of November, 2017. A 560-watt centrifugal blower with an adjustable rotary speed was used in the FP system. The tests were conducted at two levels of rotary speed of the blower ( 304 and 456rpm) and two levels of the cooling pad thicknesses ( 4 and $6 \mathrm{~cm}$ ). The blower speeds were selected based on the trials to provide the air flow rate of $0.4-0.8 \mathrm{~m}^{3} \mathrm{~s}^{-1}$ recommended by Jain and Tiwari [14]. In each test, wind speed, solar radiation intensity and temperature of different points of the greenhouse as well as ambient were measured during the day at the time intervals of 30 minutes.

A pyranometer (TES 1333R, TES co., Taiwan) was used to measure the solar intensity on the roof and the walls. Several temperature sensors (SMT 160) were employed to measure the temperature at the different points. To eliminate the effect of the radiation on the temperature data, a shiny aluminum sheet was attached to the wire of the sensor in a manner that there was a sufficient distance between the sensor and the sheet that allowed the greenhouse air to freely surround it. The temperature sensors were connected to a portable computer using a temperature transducer (TM-1323, TIKA co., Iran). To measure the relative humidity inside and outside the greenhouse a moisture meter (SUN-25H, SUNWARD co., Iran) was utilized. A blade-type anemometer (BE816A, BESTONE co., China) was used to determine the wind speed around the greenhouse. Figure 4 demonstrates the location of the different sensors during the test periods and the specification of the instruments including accuracy and range is summarized in Table 2 . The uncertainty that occurred during the experiments was calculated using the following expression [25]: 
Journal of Thermal Engineering, Research Article, Vol. 7, No. 4, pp. 918-934, May, 2021

$$
W=\sqrt{\left(w_{1}^{2}+w_{2}^{2}+\cdots+w_{n}^{2}\right)}
$$

where $W$ and $w_{n}$ are the total uncertainty and the error of $n^{\text {th }}$ factor, respectively.

Table 2. Technical specification of the measurement instruments and results of uncertainty analysis

\begin{tabular}{|c|c|c|c|c|}
\hline Instrument (Type) & Measured parameter & Accuracy & Range & $\begin{array}{c}\text { Standard } \\
\text { Uncertainty }\end{array}$ \\
\hline $\begin{array}{c}\text { Temperature sensor } \\
\text { (SMT 160) }\end{array}$ & Air temperature $\left({ }^{\circ} \mathrm{C}\right)$ & \pm 0.1 & $-30-130$ & $0.058\left({ }^{\circ} \mathrm{C}\right)$ \\
\hline RH sensor (SUN25-H) & RH of air (\%) & $\pm 3 \%$ & $0-100$ & $1.73 \%$ \\
\hline Pyranometer (TES1333 R) & Solar irradiance (W/m2) & \pm 1 & $0-2000$ & $0.58(\mathrm{~W} / \mathrm{m} 2)$ \\
\hline Anemometer (BE816A) & Air velocity (m/s) & \pm 0.1 & $0-14$ & $0.058(\mathrm{~m} / \mathrm{s})$ \\
\hline
\end{tabular}

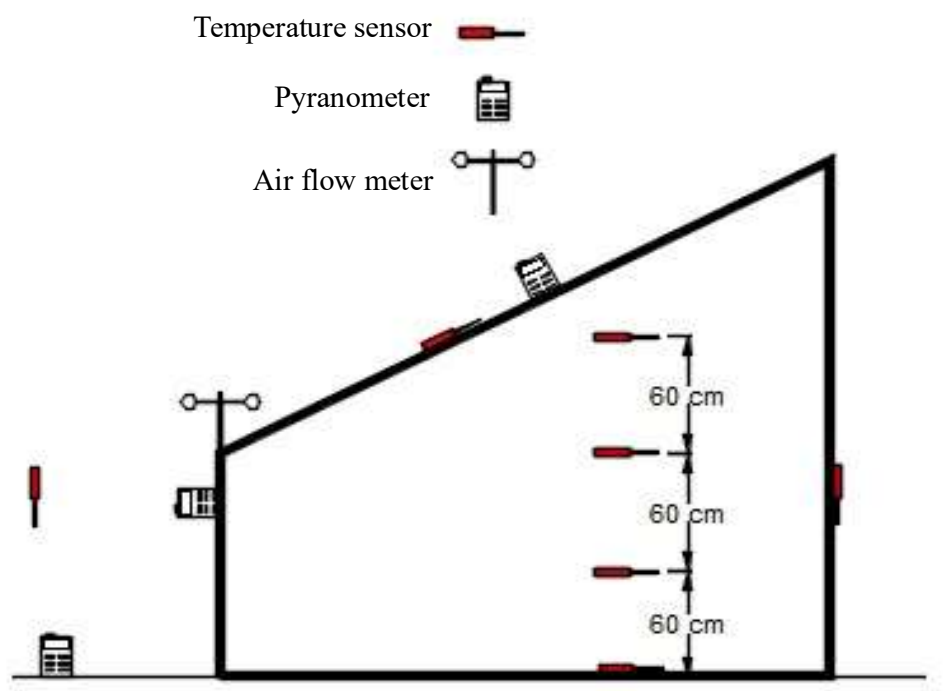

Figure 4. Location of the different sensors used during the tests

To validate the obtained expressions, their results were compared with those of the experiments, which were determined by averaging the data of the different temperature sensors located on each part of the greenhouse. For this purpose, some comparison criteria such as the correlation coefficient (r), root mean square error (e), mean absolute magnitude error (MAPE) were calculated as follow [26, 27]:

$$
\begin{aligned}
& \mathrm{r}=\frac{n \Sigma X_{i} Y_{i}-\left(\Sigma \mathrm{X}_{i}\right)\left(\Sigma \mathrm{Y}_{i}\right)}{\sqrt{n \Sigma X_{i}^{2}-\left(\Sigma X_{i}\right)^{2} \sqrt{n \Sigma Y_{i}^{2}-\left(\Sigma Y_{i}\right)^{2}}}} \\
& \mathrm{e}=\sqrt{\frac{\Sigma\left(e_{i}\right)^{2}}{n}} \\
& e_{i}=\frac{X_{i}-Y_{i}}{X_{i}} \\
& M A P E=\frac{1}{n} \sum \frac{Y_{i}-X_{i}}{Y_{i}}
\end{aligned}
$$

where $X_{i}$ and $Y_{i}$ are the $i^{\text {th }}$ theoretical and experimental data and $n$ is the number of data. 


\section{RESULTS AND DISCUSSION}

Figure 5 shows the changes in the ambient temperature and wind speed at the place and the time of the tests from 9 a.m. to 5 p.m. The highest wind speed during the experiment was about $7 \mathrm{~ms}^{-1}$ and the lowest value was $0.7 \mathrm{~ms}$ ${ }^{1}$. During this time, the ambient temperature changed from 13.9 to $21.6^{\circ} \mathrm{C}$ which were measured at 12:50 and 16:50, respectively.

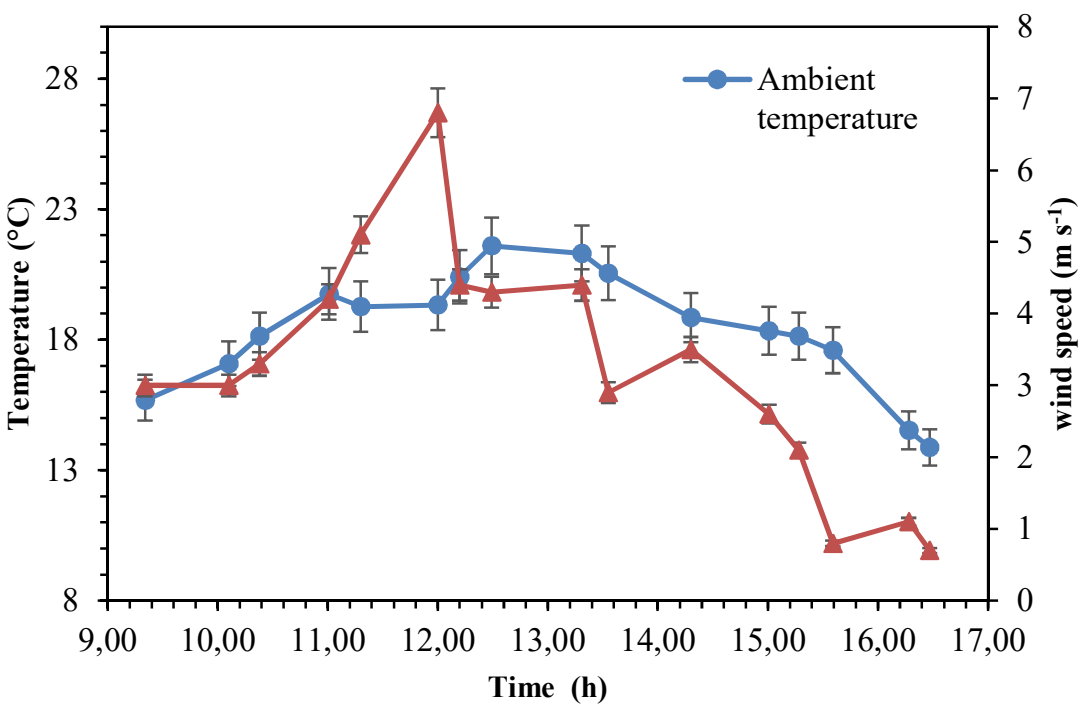

Figure 5. Variations of ambient temperature and wind speed during the test period

Figure 6 shows the solar radiation intensity on the roof, the south wall and the horizontal surface. Clearly, the sloped roof of the greenhouse had the highest and the horizontal surface had the lowest radiation intensities, which refers to the season (winter) that the experiments were conducted. However, the maximum values of the solar intensity were observed around 12 noon. Energy performance of the five typical greenhouse structures was investigated in India [28]. The results showed that the greenhouse with 20-degree sloped roof indicated the best performance, in terms of energy reception and losses.

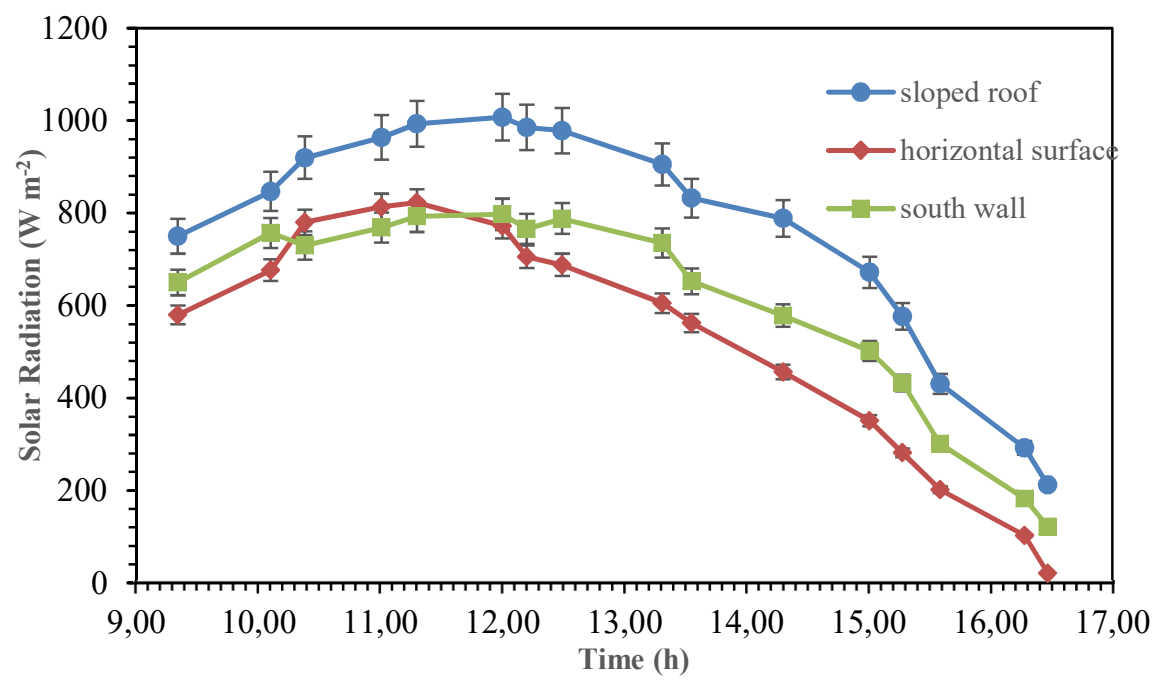

Figure 6. Variations of solar radiation intensity on sloped roof, horizontal surface and south wall 
Figure 7 shows theoretical and experimental temperatures of the roof cover, the inside air and the floor of the greenhouse under the conditions of without ventilation and cooling system. The mean temperatures of the inside air, the floor and the cover were measured to be around $47,40,44^{\circ} \mathrm{C}$, respectively. The high temperature of the greenhouse components indicates the need to use a suitable cooling system. It is clear from figure 7 that the greenhouse temperature was rising until 1 p.m. due to the gradual increase in the solar intensity and the ambient temperature. The results of the statistical comparison of the theoretical and the experimental temperatures of the different components were given in table 3. According to the table, the maximum difference between the theoretical and the experimental temperatures of the inside air, the floor, and the cover were $5.3,5.6$ and $4.5^{\circ} \mathrm{C}$, respectively. The values obtained for the correlation coefficient, mean absolute magnitude error and root mean square error were $97 \% .8 .8 \%$ and 9.7\%, respectively. Based on the obtained values for the correlation coefficient, the mean absolute magnitude error and root mean square error, it can be concluded that the obtained equations were satisfactorily able to predict the greenhouse components temperature. In a similar study conducted by Taki et al [27] the best values for the correlation coefficient, the mean absolute magnitude error, and the Wilmot revised index were $96.1 \%, 2.78$ and 97\%, respectively.

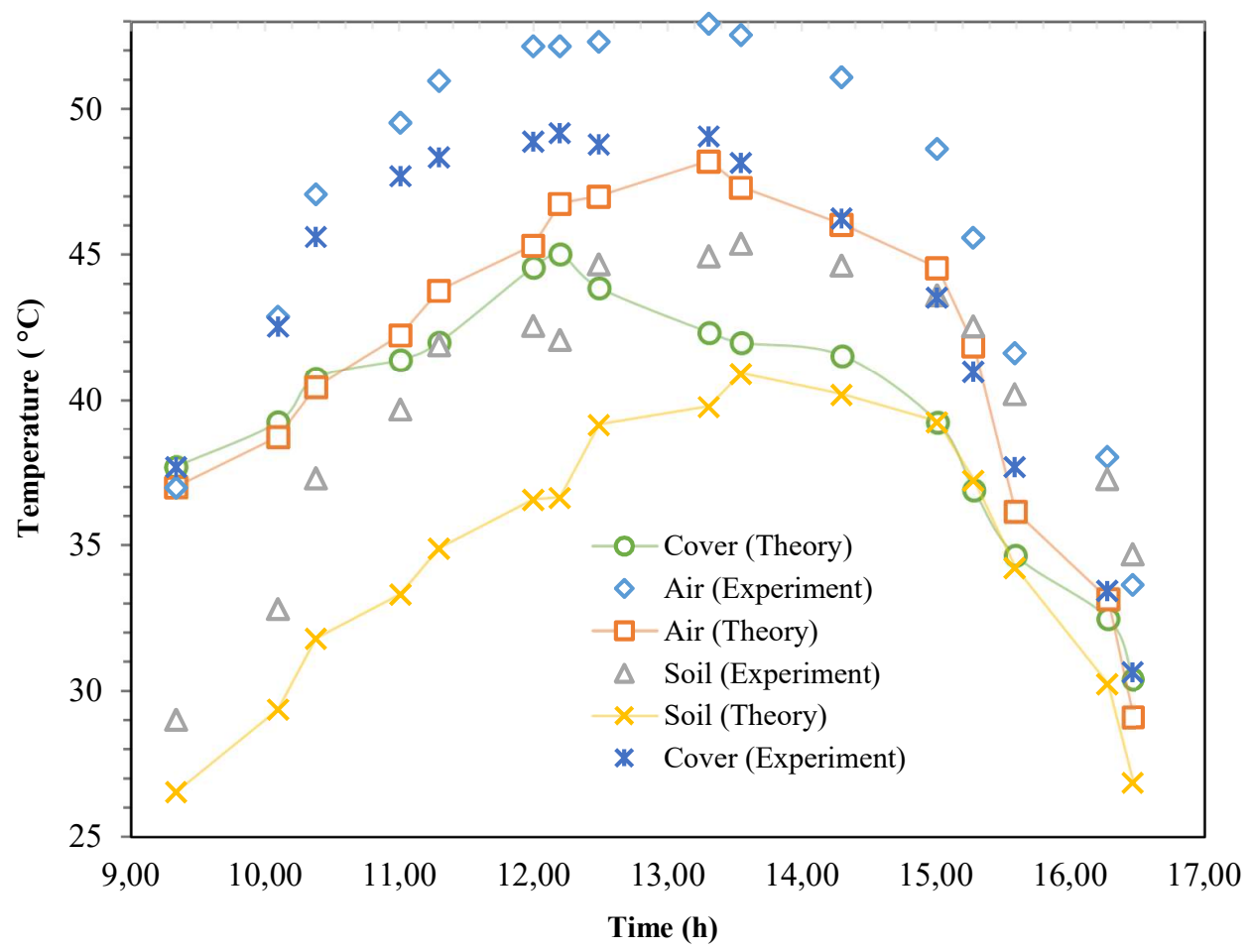

Figure 7. Theoretical and experimental temperatures of inside air, floor and cover of greenhouse without FP system

Table 3. Statistical comparison of theoretical and experimental temperatures of greenhouse without FP system

\begin{tabular}{|l|c|c|c|c|c|c|}
\hline Component & r & e \% & MAPE\% & Max & Min & Average \\
\hline Air & 96 & 11.3 & 10.7 & 53 & 34 & 47 \\
\hline Soil & 96 & 14 & 13.5 & 45 & 29 & 40 \\
\hline Cover & 97 & 9.7 & 8.8 & 49 & 31 & 44 \\
\hline
\end{tabular}


Figures 8 to 10 show the distribution of the predicted data versus the measured data of the indoor, the floor and the cover temperatures, respectively. All data are arranged close to the straight lines with the slopes of lower than one which means that the theoretical data (vertical axis) were slightly lower than the corresponding experimental data (horizontal axis). This was especially considerable in the case of the floor temperature. Similar results were observed by Taki et al [27]. This was probably because of the slight solar intensity on the east and west walls of the greenhouse which was not taken to account in the calculations. Furthermore, since the spatial difference of the temperature within the greenhouse component, especially inside air, is low at the lower temperatures, the assumption is closer to the actual condition, and achieves higher accuracy compared with the higher temperature ranges.

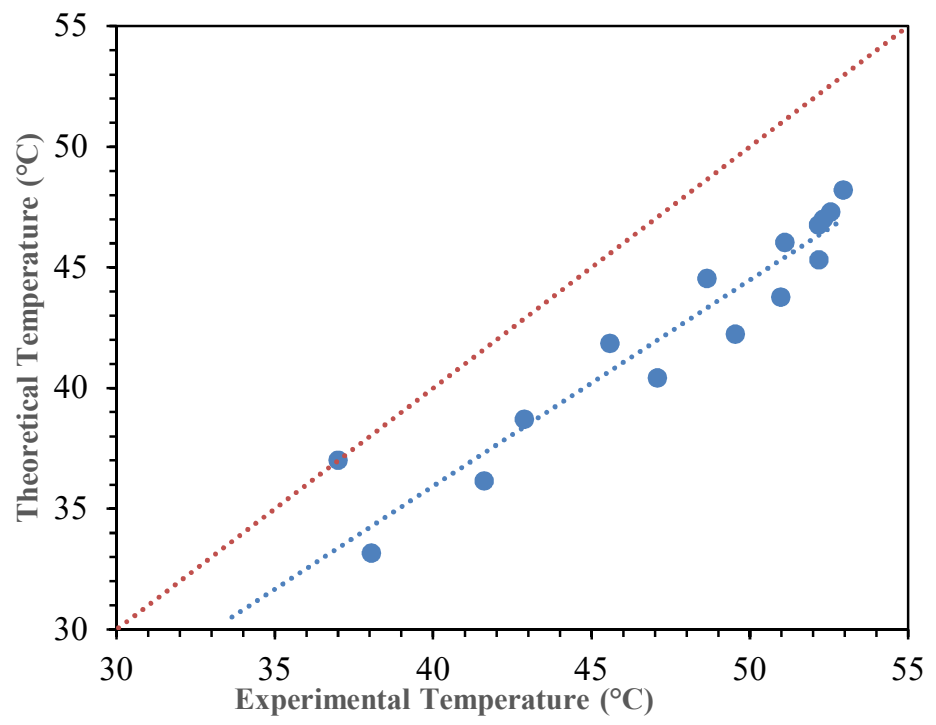

Figure 8. Theoretical versus experimental data of inside air temperature

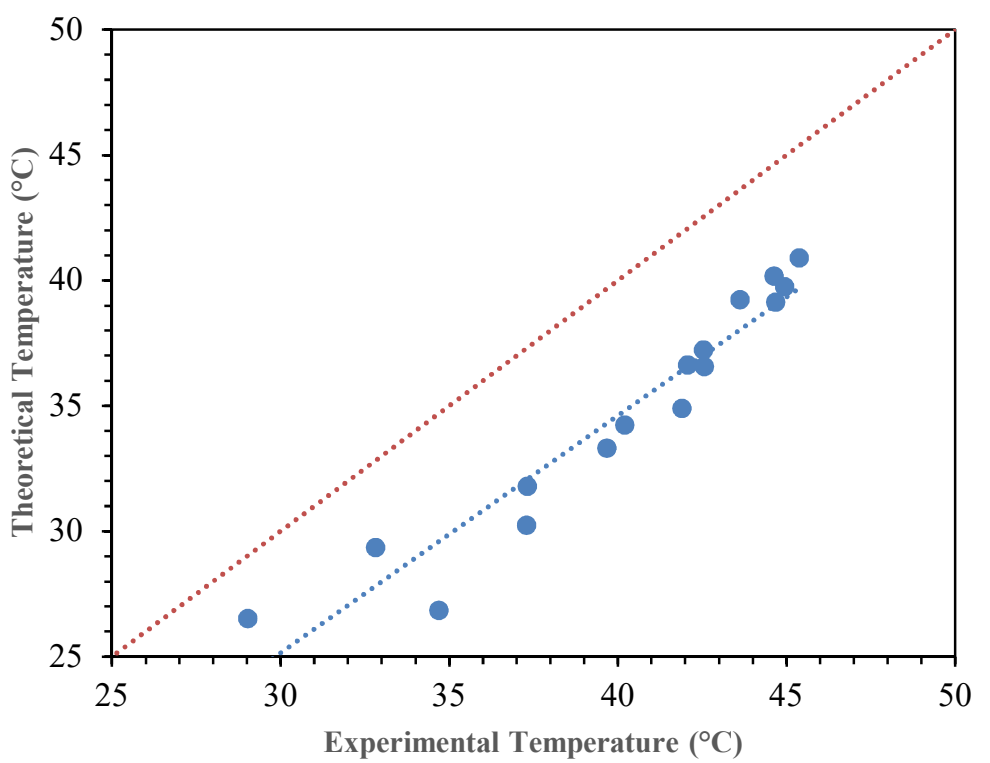

Figure 9. Theoretical versus experimental data of floor temperature 


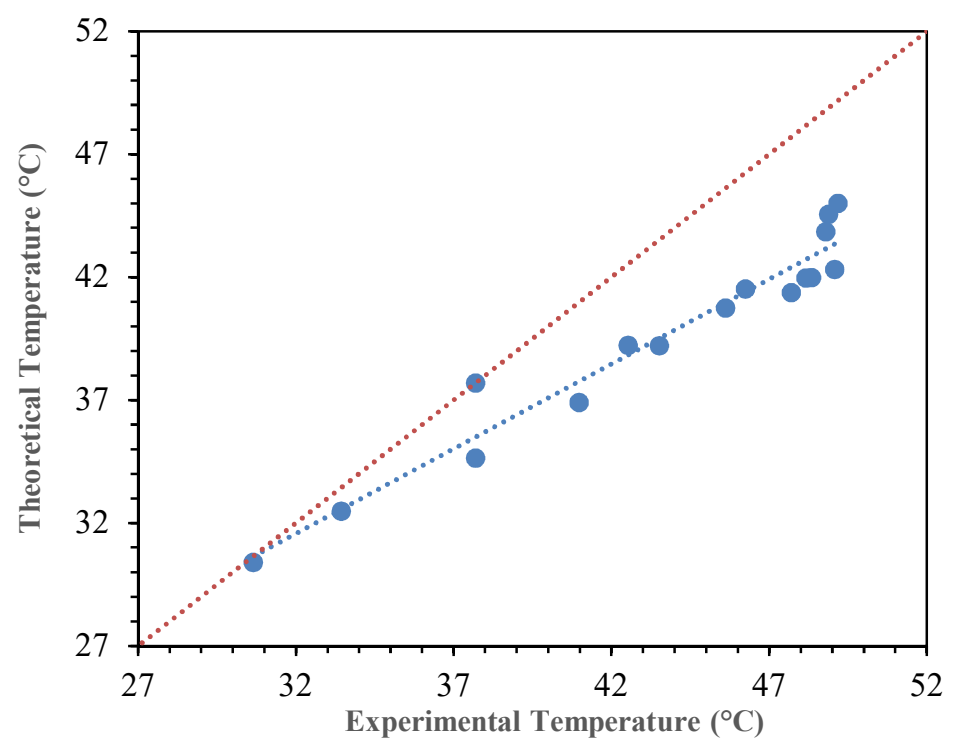

Figure 10. Theoretical versus experimental data of cover temperature

Figure 11 shows theoretical and experimental temperatures of the different components of the greenhouse when using the FP cooling system (at the air velocity of $4.4 \mathrm{~ms}^{-1}$ and the thickness of the wetted pad of $4 \mathrm{~cm}$ ). Comparison of figures 11 and 7 indicated that applying the FP cooling system could reduce the average temperatures of the inside air, the floor and the cover by 20.6, 13.0 and $20.6^{\circ} \mathrm{C}$, respectively. Kozai and Sase [29] and Landsberg et al [30] studied the performance of the FP system for greenhouses in subtropical regions. They reported that the cooling system could reduce the temperature of the greenhouses by 8 to $12^{\circ} \mathrm{C}$. Chandra et al [31] Reduced the greenhouse temperature to $4-5^{\circ} \mathrm{C}$ below the surroundings using the FP cooling system. Similar results were reported by Jain and Tiwari [14].

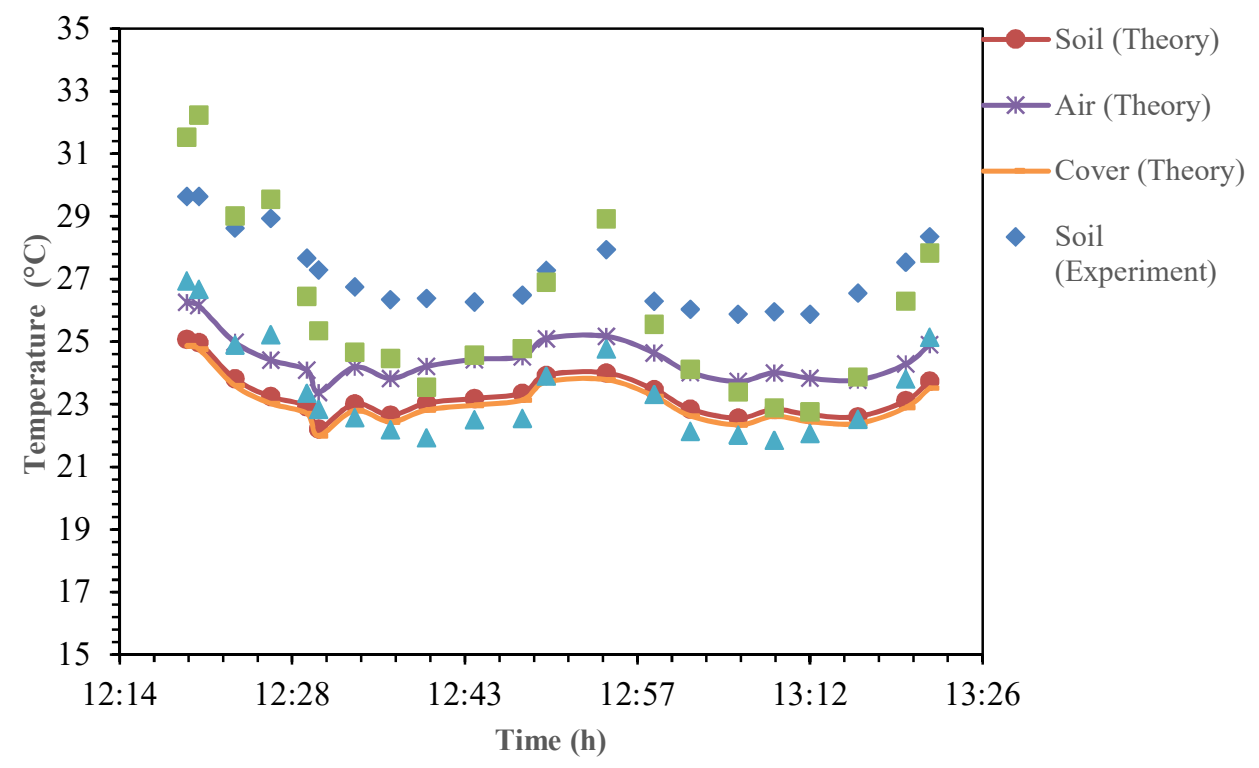

Figure 11. Theoretical and experimental temperatures of inside air, cover and floor with FP system 
Journal of Thermal Engineering, Research Article, Vol. 7, No. 4, pp. 918-934, May, 2021

The statistical comparison of the theoretical and the experimental temperatures of the greenhouse components at the different rotary speeds of the fan, and the pad thicknesses of the FP system were illustrated in tables 3-5. It is clear from table 4 that the inside air temperature slightly increased when the pad thickness increased from 4 to $6 \mathrm{~cm}$. This was because of the decrease in the air flow rate due to the increase in the pressure drop through the pad. Whereas, raising the rotary speed of the fan from 304 to 456rpm led to a decrease in greenhouse temperature by increasing the air flow rate and consequently increasing the evaporation rate. This finding is in agreement with the results of Ramkumar and Ragupathy [32].

According to the tables, changes in the correlation coefficient values were ranged between 0.30 and 0.93 . The root mean square error values were in the range of 4.14 to $18.66 \%$ and the mean absolute magnitude error varied from 1.50 to $25.67 \%$. In addition, based on the highest mean correlation coefficient and the lowest root mean square error and mean absolute magnitude error, it can be said that the obtained equations predicted the inside temperature of the greenhouse with a higher accuracy compared to the temperature of the floor and the cover. The main reason is that the inside air temperature at the vicinity of the floor and the soil has the highest deviation with its average temperature that is used in the theoretical analysis. These findings are in agreement with the results of Taki et al [27]. In addition, comparing tables 2 vs. 3-5 indicates that the theoretical analysis achieved a higher accuracy when the greenhouse was without the FP cooling system which is because of the approximations associated with the cooling system expression. Table 7 shows the comparison between the developed models in the present study with the methods described by previous researchers. It can be found that the evaluation criteria of the obtained models are in the range of the other studies.

Table 4. Statistical comparison of experimental and theoretical data of indoor air temperature using FP system

\begin{tabular}{|c|c|c|c|c|c|c|c|c|}
\hline $\begin{array}{c}\text { Pad } \\
\text { thickness } \\
(\mathbf{c m})\end{array}$ & $\begin{array}{c}\text { Rotary } \\
\text { speed } \\
\text { of fan } \\
(\mathbf{r p m})\end{array}$ & $\begin{array}{c}\text { Entering } \\
\text { air velocity } \\
\left(\mathbf{m ~ s}^{-\mathbf{1}}\right)\end{array}$ & $\mathbf{r}$ & $\mathbf{e} \%$ & MAPE\% & Mean & Max & Min \\
\hline \multirow{2}{*}{4} & 304 & 3.5 & 0.74423 & 13.82 & 13.46 & 27.0 & 29.6 & 24.4 \\
\cline { 2 - 9 } & 456 & 5.1 & 0.9336 & 12.51 & 3.32 & 25.7 & 35.2 & 20.5 \\
\hline \multirow{2}{*}{6} & 304 & 2.5 & 0.7771 & 18.57 & 17.51 & 28.0 & 30.2 & 22.4 \\
\cline { 2 - 9 } & 456 & 4.4 & 0.8535 & 9.09 & 5.64 & 26.1 & 32.2 & 22.8 \\
\hline
\end{tabular}

Table 5. Statistical comparison of experimental and theoretical data of floor temperature using FP system

\begin{tabular}{|c|c|c|c|c|}
\hline $\begin{array}{c}\text { Pad } \\
\text { thickness } \\
\text { (cm) }\end{array}$ & $\begin{array}{c}\text { Rotary } \\
\text { speed of } \\
\text { fan (rpm) }\end{array}$ & r & e \% & MAPE \% \\
\hline 4 & 304 & 0.3012 & 7.01 & 5.92 \\
\cline { 2 - 5 } & 456 & 0.9160 & 14.45 & 14.26 \\
\hline \multirow{2}{*}{6} & 304 & 0.6180 & 15.14 & 16.02 \\
\cline { 2 - 5 } & 456 & 0.7690 & 14.55 & 14.36 \\
\hline
\end{tabular}


Journal of Thermal Engineering, Research Article, Vol. 7, No. 4, pp. 918-934, May, 2021

Table 6. Statistical comparison of experimental and theoretical data of covered temperature using FP system

\begin{tabular}{|c|c|c|c|c|}
\hline $\begin{array}{c}\text { Pad } \\
\text { thickness } \\
\text { (cm) }\end{array}$ & $\begin{array}{c}\text { Rotary } \\
\text { speed of fan } \\
\text { (rpm) }\end{array}$ & $\mathbf{r}$ & $\mathbf{e \%}$ & MAPE\% \\
\hline 4 & 304 & 0.5515 & 18.66 & 18.15 \\
\cline { 2 - 5 } & 456 & 0.9297 & 16.83 & 14.25 \\
\hline 6 & 304 & 0.6463 & 26.45 & 25.67 \\
\cline { 2 - 5 } & 456 & 0.8712 & 4.14 & 1.50 \\
\hline
\end{tabular}

Table 7. Comparison of the obtained models with the methods developed by the other researchers

\begin{tabular}{|c|c|c|c|c|}
\hline Reference & Method of modelling & r & MAPE (\%) & e (\%) \\
\hline Taki et al [27] & Mass and energy balance equations & 0.961 & 2.78 & - \\
\hline Shukla et al [33] & Mass and energy balance equations & 0.87 & 10.2 & - \\
\hline Tiwari et al [34] & Mass and energy balance equations & - & 5.9 & - \\
\hline Panwar et al [35] & Mass and energy balance equations & - & $5-20$ & - \\
\hline \multirow{2}{*}{$\begin{array}{c}\text { Dariouchy et al [36] } \\
\text { Baptista et al [37] }\end{array}$} & Artificial neural network & 0.965 & - & - \\
\hline Tiwari, \& Srivastava & Mass and energy balance equations & 0.941 & - & 12.38 \\
\hline [38] & Regression & 0.55 & - & - \\
\hline \multirow{2}{*}{ Iga et al [39] } & Mass and energy balance equations & 0.937 & - & - \\
\hline \multirow{2}{*}{\begin{tabular}{c} 
Shojaei et al [40] \\
\cline { 2 - 6 }
\end{tabular}} & Artificial neural network & 0.99 & 2.4 & 1.48 \\
\hline
\end{tabular}

\section{CONCLUSIONS}

In this research, an estimation method was developed based on the mass and energy balance equations to describe the temperature variation of a greenhouse with and without the FP cooling system. The obtained results were verified using those of the experiments. The average indoor, the floor and the cover temperatures of the greenhouse without the FP system were observed to be around $47,40,44^{\circ} \mathrm{C}$, respectively. The high temperature of the greenhouse components demonstrated the necessity of using a suitable cooling system to reduce the greenhouse temperature. The results showed that the obtained models for the greenhouse without the cooling system led to the maximum deviations of 5.3, 5.6 and $4.5^{\circ} \mathrm{C}$ respectively in temperature prediction of the inside air, the floor, and the cover. In the case of using the cooling system at the air velocity of $4.4 \mathrm{~ms}^{-1}$ and the wetted pad thickness of $6 \mathrm{~cm}$, the results indicated that the FP system decreased the temperatures of the indoor, the floor and the cover by $20.6,13.0$ and $20.6^{\circ} \mathrm{C}$, respectively. Increasing the rotary speed of the fan from 304 to 456rpm decreased the greenhouse temperature, while increasing the 
pad thickness from 4 to $6 \mathrm{~cm}$ led to a slight increase in the temperature. In addition, the results revealed that the theoretical data were slightly lower than the corresponding experimental data. However, based on the observed correlation coefficient, root mean square error and mean absolute magnitude error it can be concluded that the obtained equations predicted the inside temperature with a higher accuracy compared to the temperature of the floor and the cover. It was also concluded that one source of the errors is the solar light entering the greenhouse via the west and east walls. Since such heating load is not taken into calculation, the output error will be smaller if the developed models are applied to a larger greenhouse, where the ratio of the west/east wall to the south wall surface is significantly lower. Moreover, applying an air circulation system inside the greenhouse, which provides a uniform temperature, would maintain the lumped condition even at the higher temperatures.

\section{NOMENCLATURE}

\section{$A$}

$C p$

$d$

E

F

$f$

G

k

$Q$

$T$

U

$u$

$\dot{m}$

W

Greek symbols

$\alpha$

$\Phi$

$\sigma$

$\forall$

$\rho$

$\eta$

\section{Subscripts}

a

$c a$

$d b$

g

$i$

nw

nwi

nwo

$O$

$r$

$r i$

$s$

$s k$

$w b$
Surface area $(\mathrm{m} 2)$

Specific heat capacity $\left(\mathrm{J} \mathrm{kg}^{-1} \mathrm{~K}^{-1}\right)$

Thickness (m)

Emission coefficient (dimensionless)

View factor (dimensionless)

Infiltration factor (dimensionless)

Solar radiation intensity $\left(\mathrm{W} \mathrm{m}^{-2}\right)$

Thermal conductivity $\left(\mathrm{W} \mathrm{m} \mathrm{m}^{-1} \mathrm{~K}^{-1}\right)$

Rate of heat transfer (W)

Temperature (K)

Heat transfer coefficient $\left(\mathrm{W} \mathrm{m}^{-2} \mathrm{~K}^{-1}\right)$

Air velocity $\left(\mathrm{m} \mathrm{s}^{-1}\right)$

Air flow rate to greenhouse $\left(\mathrm{kg} \mathrm{s}^{-1}\right)$

Uncertainty

Solar absorption coefficient (dimensionless)

Volumetric air flow rate to outdoor through the window $\left(\mathrm{m} 3 \mathrm{~s}^{-1}\right)$

Stefan-Boltzmann constant $\left(\mathrm{W} \mathrm{m}^{-2} \mathrm{~K}^{-4}\right)$

Volume (m3)

density $\left(\mathrm{kg} \mathrm{m}^{-3}\right)$

pad efficiency (dimensionless)

Inside air

Coolant air

Dry bulb

Greenhouse

Inlet air

North wall

Inner surface of north wall

Outer surface of north wall

Outdoor

Roof

Inner surface of roof

Soil

Sky

Wet bulb 
Journal of Thermal Engineering, Research Article, Vol. 7, No. 4, pp. 918-934, May, 2021

\section{REFERENCES}

[1] Iosif Stylianou I, Tassou S, Christodoulides P, Panayides I, Florides G. Measurement and analysis of thermal properties of rocks for the compilation of geothermal maps of Cyprus. Renewable Energy 2016;88(Supplement C):41829. https://doi.org/10.1016/j.renene.2015.10.058.

[2] Mustafa Omer A. Ground-source heat pumps systems and applications. Renewable and Sustainable Energy Reviews 2008;12(2):344-71. https://doi.org/10.1016/j.rser.2006.10.003.

[3] Benli H. Performance prediction between horizontal and vertical source heat pump systems for greenhouse heating with the use of artificial neural networks. Heat Mass Transfer 2016;52(8):1707-24. https://doi.org/10.1007/s00231-015-1723-z.

[4] Çakır U, Şahin E. Using solar greenhouses in cold climates and evaluating optimum type according to sizing, position and location: A case study. Comput Electron Agric 2015;117:245-57. https://doi.org/10.1016/j.compag.2015.08.005.

[5] Esmaeli H, Roshandel R. Optimal design for solar greenhouses based on climate conditions. Renewable Energy 2020;145:1255-65. https://doi.org/10.1016/j.renene.2019.06.090.

[6] Impron I, Hemming S, Bot GPA. Simple greenhouse climate model as a design tool for greenhouses in tropical lowland. Biosyst Eng 2007;98(1):79-89. https://doi.org/10.1016/j.biosystemseng.2007.03.028.

[7] Garcia-Alonso Y, Espi E, Salmeron A, Fontecha A, Gonzalez A, Lopez J, editors. New cool plastic films for greenhouse covering in tropical and subtropical areas2006: International Society for Horticultural Science (ISHS), Leuven, Belgium. https://doi.org/10.17660/ActaHortic.2006.719.12.

[8] Ould Khaoua SA, Bournet PE, Migeon C, Boulard T, Chassériaux G. Analysis of Greenhouse Ventilation Efficiency based on Computational Fluid Dynamics. Biosyst Eng 2006;95(1):83-98. https://doi.org/10.1016/j.biosystemseng.2006.05.004.

[9] Kumar K, Tiwari K, Jha MK. Design and technology for greenhouse cooling in tropical and subtropical regions: A review. Energy Build 2009;41(12):1269-75. https://doi.org/10.1016/j.enbuild.2009.08.003.

[10] Teitel M, Liran O, Tanny J, Barak M. Wind driven ventilation of a mono-span greenhouse with a rose crop and continuous screened side vents and its effect on flow patterns and microclimate. Biosyst Eng 2008;101(1):111-22. https://doi.org/10.1016/j.biosystemseng.2008.05.012.

[11] Ghoulem M, El Moueddeb K, Nehdi E, Boukhanouf R, Calautit JK. Greenhouse design and cooling technologies for sustainable food cultivation in hot climates: Review of current practice and future status. Biosyst Eng 2019;183:121-50. https://doi.org/10.1016/j.biosystemseng.2019.04.016.

[12] Ghosal MK, Tiwari GN, Srivastava NSL. Modeling and experimental validation of a greenhouse with evaporative cooling by moving water film over external shade cloth. Energy Build 2003;35(8):843-50. https://doi.org/10.1016/S0378-7788(02)00242-6.

[13] Ahmed EM, Abaas O, Ahmed M, Ismail MR. Performance evaluation of three different types of local evaporative cooling pads in greenhouses in Sudan. Saudi J Biol Sci 2011;18(1):45-51. https://doi.org/10.1016/j.sjbs.2010.09.005.

[14] Jain D, Tiwari GN. Modeling and optimal design of evaporative cooling system in controlled environment greenhouse. Energy Convers Manage 2002;43(16):2235-50. https://doi.org/10.1016/S0196-8904(01)00151-0.

[15] Ganguly A, Ghosh S. Modeling and analysis of a fan-pad ventilated floricultural greenhouse. Energy Build 2007;39(10):1092-7. https://doi.org/10.1016/j.enbuild.2006.12.003.

[16] Rjibi A, Kooli S, Guizani A. The effects of regeneration temperature of the desiccant wheel on the performance of desiccant cooling cycles for greenhouse thermally insulated. Heat Mass Transfer 2018;54(11):342743. https://doi.org/10.1007/s00231-018-2369-4.

[17] Van Straten G, van Willigenburg G, van Henten E, van Ooteghem R. Optimal control of greenhouse cultivation. Taylor \& Francis group: CRC press; 2010. 296 p.: https://doi.org/10.1201/b10321.

[18] Bergman TL, Incropera FP. Fundamentals of heat and mass transfer: John Wiley \& Sons; 2011.

[19] Kalogirou SA. Solar energy engineering: processes and systems. Elsevier: Academic Press; 2013. https://doi.org/10.1016/C2011-0-07038-2.

[20] van Ooteghem RJC. Optimal Control Design for a Solar Greenhouse. IFAC Proceedings Volumes 2010;43(26):304-9. https://doi.org/10.3182/20101206-3-JP-3009.00054.

[21] Vadiee A, Martin V. Energy management in horticultural applications through the closed greenhouse concept, state of the art. Renewable Sustainable Energy Rev 2012;16(7):5087-100. https://doi.org/10.1016/j.rser.2012.04.022.

[22] Joudi KA, Farhan AA. A dynamic model and an experimental study for the internal air and soil temperatures in an innovative greenhouse. Energy Convers Manage 2015;91(Supplement C):76-82. https://doi.org/10.1016/j.enconman.2014.11.052. 
Journal of Thermal Engineering, Research Article, Vol. 7, No. 4, pp. 918-934, May, 2021

[23] Mei J, Xia X. Energy-efficient predictive control of indoor thermal comfort and air quality in a direct expansion air conditioning system. Appl Energy 2017;195(Supplement C):439-52. https://doi.org/10.1016/j.apenergy.2017.03.076.

[24] Bahadori MN, Dehghani-sanij A, Sayigh A. An Analytical-Numerical Study of the Performance of New Designs of Wind Towers. Wind Towers: Springer; 2014. p. 119-47.

[25] Mortezapour H, Ghobadian B, Khoshtaghaza M, Minaei S. Drying kinetics and quality characteristics of saffron dried with a heat pump assisted hybrid photovoltaic-thermal solar dryer. J Agric Sci Technol 2014;16(1):3345 .

[26] Mortezapour H, Ghobadian B, Khoshtaghaza M, Minaee S. Performance analysis of a two-way hybrid photovoltaic/thermal solar collector. J Agric Sci Technol 2012;14(4):767-80.

[27] Taki M, Ajabshirchi Y, Ranjbar SF, Rohani A, Matloobi M. Heat transfer and MLP neural network models to predict inside environment variables and energy lost in a semi-solar greenhouse. Energy Build 2016;110(Supplement C):314-29. https://doi.org/10.1016/j.enbuild.2015.11.010.

[28] Singh RD, Tiwari GN. Energy conservation in the greenhouse system: A steady state analysis. Energy 2010;35(6):2367-73. https://doi.org/10.1016/j.energy.2010.02.003.

[29] Kozai T, Sase S, editors. A simulation of natural ventilation for a multi-span greenhouse1978: International Society for Horticultural Science (ISHS), Leuven, Belgium. https://doi.org/10.17660/ActaHortic.1978.87.3.

[30] Landsberg JJ, White B, Thorpe MR. Computer analysis of the efficacy of evaporative cooling for glasshouses in high energy environments. J Agric Eng Res 1979;24(1):29-39. https://doi.org/10.1016/0021-8634(79)90058-1.

[31] Chandra P, Singh J, Majumdar G. Some results of evaporative cooling of a plastic greenhouse. J Agric Eng Res 1989;26(3):274-80.

[32] Ramkumar R. Experimental investigation of indirect evaporative cooler using clay pipe. Journal of Thermal Engineering 2017;3(2):1163-80. https://doi.org/10.18186/thermal.298618.

[33] Shukla A, Tiwari G, Sodha M. Thermal modeling for greenhouse heating by using thermal curtain and an earth-air heat exchanger. Build Environ 2006;41(7):843-50. https://doi.org/10.1016/j.buildenv.2005.04.014.

[34] Tiwari G, Akhtar M, Shukla A, Khan ME. Annual thermal performance of greenhouse with an earth-air heat exchanger: an experimental validation. Renewable Energy 2006;31(15):2432-46. https://doi.org/10.1016/j.renene.2005.11.006.

[35] Panwar N, Kaushik S, Kothari S. Solar greenhouse an option for renewable and sustainable farming. Renewable Sustainable Energy Rev 2011;15(8):3934-45. https://doi.org/10.1016/j.rser.2011.07.030.

[36] Dariouchy A, Aassif E, Lekouch K, Bouirden L, Maze G. Prediction of the intern parameters tomato greenhouse in a semi-arid area using a time-series model of artificial neural networks. Measurement 2009;42(3):45663. https://doi.org/10.1016/j.measurement.2008.08.013

[37] Baptista F, Bailey B, Randall J, Meneses J. Greenhouse ventilation rate: theory and measurement with tracer gas techniques. J Agric Eng Research 1999;72(4):363-74.

[38] Ghosal M, Tiwari G, Srivastava N. Thermal modeling of a greenhouse with an integrated earth to air heat exchanger: an experimental validation. Energy Build 2004;36(3):219-27. https://doi.org/10.1016/j.enbuild.2003.10.006.

[39] Iga JL, Iga JL, Iga CL, Flores RA. Effect of air density variations on greenhouse temperature model. Mathematical and computer modelling 2008;47(9-10):855-67. https://doi.org/10.1016/j.mcm.2007.05.011.

[40] Shojaei MH, Mortezapour H, Jafarinaimi K, Maharlooei MM. Temperature Prediction of a Greenhouse Equipped with Evaporative Cooling System Using Regression Models and Artificial Neural Network (Case Study in Kerman City). Iran J Biosyst Eng 2019;49(4):567-76. https://doi.org/10.22059/ijbse.2018.241916.664987. 